Voix et Images

volxetimages

\title{
Bibliographie de Denis Vanier
}

\section{Jonathan Lamy}

Volume 32, numéro 1 (94), automne 2006

Denis Vanier

URI : https://id.erudit.org/iderudit/014707ar

DOI : https://doi.org/10.7202/014707ar

Aller au sommaire du numéro

Éditeur(s)

Université du Québec à Montréal

ISSN

0318-9201 (imprimé)

1705-933X (numérique)

Découvrir la revue

Citer ce document

Lamy, J. (2006). Bibliographie de Denis Vanier. Voix et Images, 32(1), 93-114.

https://doi.org/10.7202/014707ar

Ce document est protégé par la loi sur le droit d'auteur. L'utilisation des services d'Érudit (y compris la reproduction) est assujettie à sa politique d'utilisation que vous pouvez consulter en ligne.

https://apropos.erudit.org/fr/usagers/politique-dutilisation/ 


\title{
B I B L I OGRA P H IE D E DEN IS VANIER ${ }^{1}$
}

\author{
$+++$ \\ JONATHAN LAMY \\ Université du Québec à Montréal
}

\section{E U V R E S}

\section{I . 1. 1. Liv res}

+ Je, avec quatre dessins de Reynald Connolly et une préface de Claude Gauvreau, Longueuil, Image et verbe Éditions, 1965, 38 p. ; avec préfaces additionnelles de l'auteur et de Roger Des Roches, Montréal, L'Aurore, 1974, 50 p.

+ Pornographic delicatessen, préfaces de Claude Gauvreau et de Patrick Straram, Montréal, Éditions Estérel, 1968, [n. p.].

+ Catalogue d'objets de base, Saint-Simon, Éditions du Vampire, 1970, [n. p.].

+ Lesbiennes d'acid, Montréal, Parti pris, 1972, 72 p.

+ Le clitoris de la fée des étoiles, Montréal, Les Herbes rouges, 1974, [n. p.]. [La réédition dans Euvres poétiques complètes, t. I (1965-1979), Montréal, VLB éditeur/Parti pris, 1980, p. 227270, comporte quelques variantes et plusieurs images en moins.]

+ Comme la peau d'un rosaire, Montréal, Parti pris, coll. «Paroles», 1977, 61 p. [Reproduit, dans une version remaniée et sous le titre Sur la route de la soie dans Euvres poétiques complètes, t. I (1965-1979), Montréal, VLB éditeur/Parti pris, 1980, p. 309-336.]

+ L'odeur d'un athlète, Montréal, Éditions Cul Q, coll. «Mium/mium», 1978, [n. p.].

+ Euvres poétiques complètes, t. I (1965-1979), préfaces de Jacques Lanctôt et d'André-G. Bourassa, Montréal, VLB éditeur/Parti pris, 1980, 336 p.

+ Rejet de prince, préface de Suzanne Paradis et photographies de tatouages de Normand Demers, Montréal, VLB éditeur, 1983, 76 p.

+ Cette langue dont nul ne parle, préface de Jean Basile et dessins de Reynald Connolly, Montréal, VLB éditeur, 1985, 67 p.

+ L'épilepsie de l'éteint, préface de Rémi Ferland et postface d'Yvon Boucher, TroisRivières/Cesson-La-Forêt (France), Écrits des Forges/La Table rase, 1988, 45 p.

1 Étant donné le nombre considérable et la difficile accessibilité des textes ici répertoriés, on m'excusera de laisser certaines références incomplètes, notamment quant à la pagination. Je tiens par ailleurs à remercier Richard Gingras de la librairie Le chercheur de trésors ainsi que Mario Brassard des êditions Les Herbes rouges pour leur précieux coup de main. 
+ Les stars du rodéo, avec quatre encres de Reynald Connolly, Trois-Rivières, Écrits des Forges, 1990, $78 \mathrm{p}$.

+ Hôtel Putama. Textes croisés, Longueuil-New York, 1965-1990, préface de Rémi Ferland, postface de Lucien Francoeur et illustrations de Louise Néron, Québec, Éditions de la Huit, 1991, $153 \mathrm{p}$.

+ Une Inca sauvage comme le feu, poèmes biologiques, illustrations de Robin Williams, Québec, Éditions de la Huit, 1992, 66 p. Édition limitée à 200 exemplaires numérotés.

+ L'hôtel brûlé, dessins de Renald Connolly, Trois-Rivières/Moncton/Pantin (France), Écrits des Forges/Éditions Perce-Neige/Le Castor Astral, 1993, 89 p.

+ Je ne reviendrai plus (textes choisis 1970-1994), préface d'Yves Boisvert, Montréal, Espace global, 1994, $52 \mathrm{p}$

+ Le fond du désir, Montréal, Les Herbes rouges, 1994, 66 p. ill.

+ Renier son sang, Montréal, Les Herbes rouges, 1996, 71 p. ill.

+ La castration d'Elvis, Montréal, Les Herbes rouges, 1997, 53 p. ill.

+ Tu me trompes avec un oiseau, Montréal, Les Herbes rouges, 1998, 73 p.

+ Le baptême de Judas, Montréal, Les Herbes rouges, 1998, 67 p.

+ Noyée dans le bain avec son chat, Québec, Docteur Sax, 1998, [26 p.].

+ L'urine des forêts, Montréal, Les Herbes rouges, 1999, 78 p.

+ Porter plainte au criminel, avec cinq dessins de Guy Boutin, Montréal, Les Herbes rouges, 2001, $103 \mathrm{p}$.

\section{I.1.2. Livres en collaboration}

+ Koréphilie, en collaboration avec Josée Yvon, Trois-Rivières, Écrits des Forges, coll. «Radar», 1981, $51 \mathrm{p}$.

+ Phases critiques, en collaboration avec Micheline Gagnon, Serge Grenier et Josée Yvon, Montréal, Éditions transpercées, 1983, 38 p. Édition limitée à 100 exemplaires numérotés.

+ L'âme/défigurée, en collaboration avec Josée Yvon, dessins de Normand Demers, Talence (France)/Herstal (Belgique), Le Castor Astral/l'Atelier de l'Agneau, 1984, 42 p.

+ Travaux pratiques, t. I (1970-1984), en collaboration avec Josée Yvon, préface de Rémi Ferland, Sainte-Foy/Montréal, Éditions Rémi Ferland/Éditions transpercées, 1987, 207 p. Édition limitée à 60 exemplaires.

+ Vanierama, en collaboration avec Richard Gingras et Robert Tanguay, illustrations de Guy Boutin, Montréal, Le Relieur fou, 1997, [n. p.]. Livre-objet accompagné d'une cassette audio et d'une cassette vidéo. Édition limitée à 15 exemplaires.

\section{I.2. Préfaces et postfaces à des livres}

+ Claude Beausoleil, Journal Mobile, Montréal, Éditions du Jour, 1974, p. 7-15.

+ Denis Boucher, Tamtam rouge, Montréal, Parti pris, coll. «Paroles», 1978, [n. p.]. En collaboration avec Josée Yvon.

+ Paul Chamberland, Le prince de sexamour, Montréal, l'Hexagone, 1976, p. 7-8. En collaboration avec Josée Yvon.

+ Francine Déry, Les territoires de l'excès, Saint-Lambert, Éditions du Noroît, 1990, p. 5-9.

+ Gilles Groulx, Poèmes, Montréal, Les Herbes rouges, 1974, [n. p.].

+ Josée Yvon, Filles-commandos bandées, Montréal, Les Herbes rouges, 1976, [n. p.]. [Reproduite dans Josée Yvon, Danseuses-mamelouk, Montréal, VLB éditeur, 1982, p. 146-147.] 


\section{I.3.1. Poèmes parus dans des périodiques a u Québec}

+ «Décombres», Parti pris, vol. 3, n 9, avril 1966, p. 36-37.

+ «[les écormats lambrissaient...]", Allez chier, n 1, mars 1969. [Contribution à l'événement \# 10 de Serge Lemoyne.]

+ "Allô-police», Logos, vol. 3, n 4, juillet-août 1970.

+ «French kiss», Logos, vol. 3, n 5, août-septembre 1970, p. 9. [Comporte des extraits écrits en anglais.]

+ «Mustard Darling», « $1 \mathrm{lb}$. de beurre», «La poche royale», «Overdrive palace» et «Lesbiennes d'acid», Ether, nº 3, novembre 1970, p. 2-7.

+ «Sulfate de magnésium alpha-tocoférum», Hobo-Québec, n 3, mars 1973, p. 2.

+ «Taverne Vanier», Hobo-Québec, nos 5-7, septembre 1973, p. 4-5.

+ «La 303 suprême dont les balles ne tuent pas», Cul-Q, nos 8-9, janvier 1976, p. 53-61. [En alternance avec, sur les pages paires, «Pour une autopsie de la mort brutale sans éviction du jour au lendemain ", de Josée Yvon.]

+ "Vanier lu par Jenny Rock», Hobo-Québec, nºs 27-28, janvier-avril 1976, p. 25.

+ «L'odeur d'un meurtrier est plus sexuelle que celle d'un athlète», Hobo-Québec, n 31 , septembre-décembre 1976, p. 22.

+ "L'état de grâce par l'invagination", Hobo-Québec, no 32, janvier-mars 1977, p. 13.

+ «Menstrués de rock», Hobo-Québec, n³3, avril-juin 1977, p. 10-11.

+ "Les peaux de loups me saignent dans le dos mais il suffit de pomper le règne animal», HoboQuébec, no 34, septembre-novembre 1977, p. 12-13.

+ «L'amour impérial», Hobo-Québec, no 35, janvier 1978, p. 16-17.

+ «Dans la chambre des joueurs la solitude s'est faite jeune fille», Hobo-Québec, nos 36-37, janvier-mars 1979, p. 12-13.

+ «Syspurderme», Hobo-Québec, nos 38-39, automne 1979, p. 8-9.

+ «Irrigation et infantilisme», Hobo-Québec, n 40, hiver 1979-1980, p. 7.

+ «[affiche-poème] », Impact, nº 4, janvier 1980.

+ «Monstroma», Virus, vol. 3, no 2, avril 1980, p. 15.

+ "Les baisers", Hobo-Québec, no 41, été 1980, p. 4-5.

+ «Mark-ten», Hobo-Québec, nº 43, hiver 1980-1981, p. 22-23.

+ "Les peaux des loups», Intervention, $\mathrm{n}^{\text {os }}$ 10-11, printemps 1981, p. 58.

+ «Effets secondaires », Hobo-Québec, nos 44-45, printemps-été 1981, p. 4-5. [Un collage fait par Denis Vanier et Josée Yvon se trouve à la page 44 de la revue.]

+ «Liniment de mage» et «Décharge», Hobo-Québec, nos 46-47, automne 1981, p. 43 et 50.

+ «Dans la chambre des joueurs», Le Berdache, n²3, septembre 1981, p. 55.

+ «Liniment de mage», Le Berdache, n 24, octobre 1981, p. 53.

+ «Irrigation et infantilisme», Le Berdache, n 25, novembre 1981, p. 60.

+ «Mark-ten en retenue», Le Berdache, no 26, décembre 1981-janvier 1982, p. 61.

+ "La reine des bandits», Intervention, n 21, hiver 1983, p. 29.

+ "Sept poèmes», La Nouvelle Barre du jour, nos 122-123, février 1983, p. 197-204.

+ "Quatre poèmes», La Nouvelle Barre du jour, no 125, avril 1983, p. 5-11.

+ "Codéine» et «Dans la chambre des joueurs», Dixit.01, vol. 1, n 1, hiver 1984, p. 40-41.

+ «Le journal du peuple», La Nouvelle Barre du jour, nº 140, juin 1984, p. 119.

+ «Le droit de sainteté», Dérives, n 50, septembre 1985, p. 87-88.

+ «L'électrolyse masculine», Dixit.01, vol. 1, n 3, hiver 1985, p. 45-46. 
+ «L'épilepsie de l'éteint», Mœbius, n 28, printemps 1986, p. 71-72.

+ «Et c'est ainsi depuis», Estuaire, nos 40-41, mai 1986, p. 117-119.

+ «Et c'est ainsi depuis», Dixit.01, n 8, 1986, p. 13.

+ "L'épilepsie de l'éteint», «Le droit de sainteté» et "Ses larmes liquides», N'importe quelle route, vol. 1, n² 2, 1987, p. 40-45.

+ «Les sœurs de Zeynab», Mœbius, n 36, printemps 1988, p. 107-108.

+ «Elvis Ti-Jean», N'importe quelle route, vol. 2, nº 1, avril 1988, p. 46.

+ «Kundalinî heavy-métal», N'importe quelle route, vol. 2, no 3, décembre 1988, p. 29.

+ «Mon plus grand rêve», Passages, n 16, automne 1988, p. 61-62.

+ "[Handicapés ne vous soignez plus...] », «Les semis de s'abattre», "Cigare et citron» et «La sorcière est le plus beau bijou du démon », N'importe quelle route, vol. 3, nº 1, printemps 1989, p. 36-37.

+ «Chick» et «Les produits domestiques», N'importe quelle route, vol. 3, n 2, automne 1989, p. $44-45$.

+ «Abattu pour avoir créé comme un cochon embaumé», Gaz moutarde, n 9, 1991, p. 31-34. [Repris dans Gaz moutarde, nos 16-17, «Anthologie corrosive», 1994, p. 83-85.]

+ «Une Inca sauvage comme le feu et la délicatesse de son sacrement sur la table de pool du chalet de l'agonie», Gaz moutarde, no 13, été 1992, p. 29-32.

+ «La discipline du désir», Gaz moutarde, n 16, printemps 1993, p. 41-44.

+ «Sucre brûlant» et «Sauvage comme le feu», Espace global, n 5, été 1993, p. 19-21.

+ "La laideur des trophées», "Basse comme les Laurentides», "La matière de la beauté» et «La délicatesse des victimes», Espace global, nº 12, été 1994, p. 45-46.

+ «La mangeuse de chairs» et «Une tache de sang aux tempes de l'amour», Le Sabord, n 38, automne 1994, p. 3 et 18.

+ «Lettre morte à l'inerte», Estuaire, n 77, avril 1995, p. 51-54.

+ «Vendre sa mère», Lectures, vol. 2, no 10, juin-juillet 1995, p. 10.

+ «Je me dois à la rue», L'Action nationale, vol. 85, n 9, «Hommage à Gérald Godin", novembre 1995, p. 215.

+ «L'idée d'homicide», Possibles, vol. 20, nº 1, hiver 1996, p. 125-133.

+ «Des images pour interner», Le Sabord, nº 43, printemps-été 1996, p. 7.

+ "Je veux devenir une fleur aux couleurs déflorées de gelée lima», "L'unique est tabou» et «Ses yeux de Gaspésienne», Le Sabord, n 46, printemps-été 1997, p. 35.

+ «L'humilité», «La saveur», «L'homme-génocide» et «Mourir sur la table», Le Sabord, n 49, printemps 1998, p. 28.

+ «Fais d'la marde», Steak haché, nº 0, juin 1998.

+ «Le mensonge des couleurs», Steak haché, nº 1, juillet 1998.

+ "L’horreur des fruits», Steak haché, nº 2, août 1998.

+ "L'été s'éteint en chaise roulante», Steak haché, nos 3-4, septembre 1998.

+ «Embrasser avec du sang», Steak haché, nº 5, septembre 1998.

+ «L'horreur des fruits», «La peine», "Chien yang» et «Le péché», Mœbius, n 79, automne 1998, p. 13-14.

+ «La morve des bonbons», «Mourir d'amour est un jeu d'enfant» et "Pourquoi tirer dans face quand on peut poignarder dans le dos», Steak haché, n 6, octobre 1998.

+ «Talisman", «Le cloître», «Demain est un feu de forêt», "Est-ce la dernière fois que nous nous voyons», «Boire devant le téléphone» et «L'écorné», Steak haché, nº 7, novembre 1998. 
+ «Fourrer le chien », «Le matelas de ma mère», «18 ans 1/2 » et «Fourrer le 220 », Steak haché, nº 8, décembre 1998.

+ «[Rouler des cigarettes au froid...] ", «Le sport de se briser», «La morsure » et "L'urine des forêts", Steak haché, no 9, janvier 1999, p. 2, 5 et 20.

+ «Disloquer dans le mur», "Sois indulgente avec la peur», "Masqué comme un civil», «Ressuscité des vivants» et «L'agonie est ma dernière mère», Steak haché, no 10, février 1999, p. 13 et 15 .

+ «Tout perdre n'est rien», «Disloqué dans le mur», «Masqué comme un civil» et «Je me contente de si peu», Steak haché, n 11, mars 1999, p. 7 et 16.

+ «La traite des Blanches», «Son masque sentait bon», «Combien ont voulu me laver», "Tu ne mangeras plus», «Le coureur de fond» et «Quand le pain tombe», Steak haché, n 12, 25 avril 1999, p. 3, 18 et 21.

+ «L'urine des forêts», Estuaire, no 97, mai 1999, p. 74-80.

+ "Pénétrer dans la chambre», "En prison, on chie devant tout le monde», "Elle guérit l'eau », «L'intimité de l'ordre», «Fausse couche» et «Le maudit courage», Steak haché, n 13, mai 1999, p. 4, 7, 29 et 31 .

+ «L'espoir», "L'amour des monstres», «Les mains arides», "L'heure avancée» et «La douleur des étoiles", Steak haché, no 14, juin 1999, p. 4, 5 et 38.

+ «Je te tuerai au ciel», «Le barrage des excès», "Mais que dis-je», «Il m’en faudrait si peu», «L'espoir», «Les médicaments ne font plus effet» et «La mort est constamment vivante», Steak haché, $\mathrm{n}^{\circ} 15$, juillet 1999, p. 3, 7 et 8 .

+ «Un faux pas dans l'absolu», «Maintenant que je quitte mon corps», «Demerol», «L'étreinte de l'espèce», «La douleur logique» et « [je ne sais plus rien...] », Steak haché, no 16, août 1999, p. 5 et 37.

+ «La poche et le masque», "Passé date», «Aux barricades» et «Les feuilles du matin», Steak haché, n 17 , septembre 1999, p. 9 et 22.

+ «La torture du silence», «On en trouve dans le commerce», «Le spectre», «L'eau qui blesse» et «Tu ne t'en sortiras pas», Steak haché, nº 18, octobre 1999, p. 11 et 37.

+ «Bain de sang», «La méchanceté» et «La déchéance», Steak haché, nº 19, novembre 1999, p. 5.

+ «Porter plainte au criminel», «La vocifération » et «L'horizon fracassée, Steak haché, n 20, décembre 1999, p. 2.

+ "Quand les médicaments ne font plus effet» et «Douleur sucrée», Steak haché, nº 21, janvier 2000, p. 9.

+ «L'évidence» et "Menacé», Steak haché, n² 22, février 2000, p. 5.

+ «Lampe de Chine» et «Pourquoi ces mots avaient-ils besoin de se cacher dans ce livre?», Steak haché, $\mathrm{n}^{\circ} 23$, mars 2000, p. 20-21 et 30.

+ «Infinité» et «Deux minous moururent d'asphyxie», Steak haché, nº 24, avril 2000, p. 3.

+ "Quand il mourra poignardé», «Les instruments», «Pour la dernière fois » et " [Maintenant je vois à travers l'invisible...] ", Steak haché, n² 25, mai 2000, p. 9, 16 et 21.

+ "Bleu comme tes cuisses», "La cuisine dans la nuit», "En rentrant de l'école», "Arraché» et «Des mots absolus», Steak haché, no 26, juin 2000, p. 5 et 37.

+ «Le jour où il tomba», «La vengeance des anges», "L'aquarium maudit» et «Nœud et poison", Steak haché, n² 27, juillet 2000, p. 5, 13 et 34 .

+ "[J'ai dû connaître où je suis né...] », «La chaleur», «Faux bijou», «Une doudou peut se brancher» et «L'eau glacée de diamants», Steak haché, n 28, août 2000, p. 3, 22-23 et 37. 
+ «Le Tintoret poignardé», «Poudre religieuse», "Après la mutation/durant la finalité » et «Robe de mariage», Steak haché, no 29, septembre 2000, p. 3-4, 7 et 9.

+ "C'est la fin d'un seul livre», "La cravate blanche à l'eau de javel » et «L'écriture en cutup », Steak haché, nº 30, octobre 2000, p. 2-3. [Poèmes posthumes.]

+ «L'espoir du père» et «Literie», Steak haché, nº 100, août 2006, p. 22-23. [Poèmes inédits, reproduits en version manuscrite.]

\section{I.3.2. Poèmes parus dans des périodiques hors Québec}

+ "Avant l'attentat aux mœurs", Cavalier seul, bulletin publié par Cheval d'attaque (France), n 7 , mai 1974, p. 12-13.

+ «Effets secondaires», Mensuel 25. Journal d'urgence tiré à blanc (Belgique), n 52, septembre 1981, p. 6-7.

+ «Irrigation et infantilisme», Le Point d'ironie (Allemagne), n 6, mars 1982.

+ «[L'absence morne...]», Poésie 1 (Paris), nos 96-98, mars-avril 1982, p. 208-209.

+ «[titre inconnu] », Mensuel 25 (Belgique), nº 69, février 1983.

+ «St-Julien l’hospitalier», M25/Photomontages (Belgique), juin 1983, p. 51-53.

+ «Blue stratos», Foldaan (France), n 4, octobre 1983, p. 6.

+ «Lesbiennes d'acid», «[mouillées d'amour...] » et «Syspurderme», Action poétique (France), no 93,1983, p. 46-48.

+ «Le poète et la mutation physique», Strass polymorphe (France), n 2, septembre 1984.

+ «L'insubstantation» et «Depro-provero», Dalhousie French Review (Halifax), avril 1985, p. 118-122.

+ «Le sérail des Hébreux», Oz-!t (France), nº 8, avril 1985, p. 21-23.

+ «Ses larmes liquides», Oz-!t (France), n 9, juin 1985, p. 20.

+ «Rejet de prince», Pli (France), nº 11, février 1986, p. 4.

+ «[épuisés sur la glace...]», Pli (France), nº 12, mars 1986, p. 33.

+ «Liniment de mage», Alba (France), n 4, avril 1986, p. 8.

+ «Ses larmes liquides», Pli (France), no 14, mai 1986, p. 19-21.

+ «Poèmes», Regart (Belgique), n 1, mai 1986, p. 12-13.

+ «Blues», Pli (France), no 15, juin 1986, p. 19-21.

+ «Depro-provero», Vagabondages (France), nº 66, mars 1987, p. 52.

+ "Les bijoux du démon", Si brève l'ire (Allemagne), no 12, octobre 1987, p. 9-10.

+ «L'épilepsie de l'éteint» et «L'agression de l'état de grâce», Levée d'encre (France), nºs 3-4, avril 1988, p. 25-30. [Ce numéro double est dédié à Patrick Straram.]

+ «Le droit de sainteté», Rampike (Toronto), vol. 6, n 2, janvier 1989, p. 57.

+ «Meurtre de l'auteur», M25 (Belgique), nº 140, mars 1989, p. 3.

+ «Bibliothèque d'homme», Europe (France), n 839, mars 1999, p. 228-230.

\section{I.4. Poèmes et textes co-écrits avec Josée Yvon}

+ «Nouvelles de l'Est», Hobo-Québec, nos 16-17, février-mars 1974, p. 4-6.

+ «L'Est coprophagique», Hobo-Québec, nº 18, avril-mai 1974, p. 16-17.

+ «Tuer, fourrer, manger», Hobo-Québec, nos 19-20, juin 1974, p. 3-4.

+ «Concerto pour 3 paranoïas», en collaboration avec Paul «Merlin» Chamberland, Mainmise, $\mathrm{n}^{\circ} 49,1974$, p. 27-31.

+ «Transpercées », Hobo-Québec, nos 21-22, janvier-avril 1975, p. 8-11. [Une photographie de Denis Vanier se trouve en quatrième de couverture de la revue.] 
+ "Ginette hybride en chaleur», Hobo-Québec, nos 23-24, mai-août 1975, p. 4-5.

+ «Vers une bombe du peuple», Hobo-Québec, nos 25-26, septembre-décembre 1975, p. 20-22.

+ "L'écriture», Dérives, nº 1, septembre-octobre 1975.

+ "Offerts à la chasse», Hobo-Québec, nos 29-30, mai-août 1976, p. 12-13.

+ «Pierre Monat, ceinture noire en amour», Cahiers, n 6, été 1980, p. 26-27.

+ «Le perçage du corps», Sortie, nº 6, avril 1983, p. 3-4.

+ «Pour le meilleur et pour le pire. Léo Lévesque parle», Sortie, nº 8, juin 1983, p. 28-29.

+ «Normand Demers, le seul tatoueur du nouveau village de l'Est», Sortie, nº 17, mai 1984, p. 16.

+ «La première galerie d'arts carcéraux en Amérique du Nord. La Galerie Maximum, au 123 ouest, rue Mont-Royal», Sortie, nº 19, juillet 1984, p. 29.

\section{I . 5 . 1. É t u d e s}

+ «La viande et ses effets biochimiques», Mainmise, n 2, décembre 1970, p. 148-152.

+ "L'usage récréationnel des vaso-dilatateurs coronariens», Attitude, vol. 1, nº 1, 1978.

+ "Ce qu'il faut aussi savoir sur les "poppers"», Hobo-Québec, nos 36-37, janvier-mars 1979, p. 50.

+ «La drogue du rock et du sexe», Le Berdache, n² 27, février 1982, p. 56-58.

+ «La marginalisation de Jack Kerouac par la Beat Generation», Pierre Anctil, Louis Dupont, Rémi Ferland et Éric Waddel (dir.), Un homme grand. Jack Kerouac à la confluence des cultures, Ottawa, Carleton University Press, 1990, p. 115-121.

\section{I.5.2. Critiques littéraires}

+ "The End of the Road de John Barth" et «The Cool Beyoltz Cycle de Jack Hirschman", Mainmise, n 63, octobre 1976, p. 35.

+ «Doberman d'amour», Mainmise, n 64, novembre 1976, p. 34.

+ «Ā jeun dans la terreur/du corps évacué par/la bouche de l'amour/nous sommes le lavement sacremental", Mainmise, no 65, décembre 1976, p. 45.

+ "The First Third de Neal Cassady», "The Steps (Les Pas) de Jerzy Kosinki», «SS regalia de Jack Pia», "Show Me. A Picture Book of Sex for Children and Parents», "The Queens de Georges Alpert», «Lyripol de Jack Hirschman», «Some Call it Kitsch d'Aleksa Celebonovic» et «Beatitude, nº $25 »$, Mainmise, n 66, janvier 1977, p. 44-45.

+ «Imperial bondage», «Sex Freaks. Simons's Book of World Sexual Records Illustrated», "Punk magazine, n 4, vol. 1 ", "A Bachelor's Guide to Brothels of Nevada de Gerald Paine», «Chic, $\mathrm{n}^{\circ} 1$ » et «Purple Submarine de Jack Micheline», Mainmise, n 67, février 1977, p. 44-45.

+ «Little Girls», «Female Masturbation, no 11 », «Police Actors Workshop », «Investigative Poetry d’Ed Sanders» et «Sexual Devices», Mainmise, n 68, 1977, p. 43.

+ "Mexico City Blues de Jack Kerouac», «Interview, vol. 1, no 12, mensuel dirigé par Andy Warhol» et «Microbs and Morals de Theodore Rosebury», Mainmise, n 69, 1977, p. 45.

+ «Leatherman's Handbook de Larry Townsend» et «The Castle Report d'Ed Sanders», Mainmise, $\mathrm{n}^{\circ} 71,1977$, p. 35.

+ «The Razor's Edge», Mainmise, n 72, 1977, p. 40.

+ «Mémoires d'un vieux dégueulasse de Charles Bukowski» et «Illustrated Book of Tatoos», Mainmise, n 73, 1977, p. 41.

+ «Being There et Cockpit de Jerry Kosinki», «The Poems of Al Purdy», «The New Handbook of Prescription Drugs ", "Another Country de James Baldwin » et "Gay Liberation in Canada", Mainmise, no 74,1977, p. 41. 
+ "The Arcanes of Le Comte de St-Germain de Jack Hirschman", "English Eccentrics de Edith Sitwell» et «Dust Bowl Motel Poems de Claude Washburn [Claude Pélieu]», Mainmise, nº 75, 1978, p. 42-43.

+ «Neurologique» et «Pornographie punk», Mainmise, n 76, 1978, p. 76.

+ "Apocalypses de R.A. Lafferty", "Falconer de John Cheever», «Herzog de Saul Bellow» et «Le gauchisme de Park Avenue de Tom Wolfe», Mainmise, n 77, 1978, p. 45.

+ «La princesse Elaine de Gene Bilbrew» et «Jewish American Literature de Abraham Champan», Mainmise, no 78, 1978, p. 45.

+ "Tatoué dans le sang de la police. Vermillon de Nathan Aldyne», Le Berdache, n 27, février 1982, p. 60-61.

\section{I.5.3. Critiques musicales}

+ «L'amphétamine rock contre les WHO», Mainmise, no 1, octobre 1970, p. 50-57.

+ "Une à une de Nanette Workman", Chansons, vol. 19, n 1, 1996, p. 22-23.

+ «France Gall par France Gall», Chansons, vol. 19, n 2, 1996, p. 28-29.

+ «Amérock du Nord de Corbach», Chansons, vol. 19, n 5, 1997, p. 30-31.

\section{5.4. Critiques $\mathrm{d}^{\prime}$ a rt}

+ «Coups et blessures, sans lumière», Hobo-Québec, nº 43, hiver 1980-1981, p. 51. [Repris en partie dans la revue Cahiers, no 12, février 1981, p. 7.]

+ «Hurtubise ou le sport du non-imaginaire» [texte et propos recueillis], Propos d'art, vol. 4, nº 4, décembre 1981, p. 6-7.

\section{I.5.5. Textes divers en prose}

+ «J'écris pour... transcender l'objet nul», La Presse, 17 janvier 1970, p. 26.

+ «[Préface de Denis Vanier au livre La libération technique de Suzanne Francoeur refusée par Lucien Francoeur...]», Hobo-Québec, n 4, avril-mai 1973, p. 4.

+ «Poètes californicateurs», Revue d'esthétique, nos 3-4, 1975, p. 152.

+ «Festival 16 mm», «Les étrangleurs du rock» et «Vêtements papillon», Mainmise, n 76, 1978, p. 12-13.

+ «La Mère Michel, 18 mois », " 18 semaines de films soviétiques» et «Les tatoués» [sur une exposition de photographies de Josée Yvon], Mainmise, no 77, 1978, p. 9 et 13.

+ «La pornographie. Science religieuse, en pleine pubiotomie carnivore», Le Berdache, nº 3 , septembre 1979, p. 29.

+ «L'érotisme du baroque», Le Spasme de vivre, vol. 2, octobre 1984, p. 61-62.

+ "Ma rencontre avec Kerouac», N'importe quelle route, vol. 1, n 3, octobre 1987, p. 16-17. [Repris avec quelques variantes dans Hôtel Putama. Textes croisés, Longueuil-New York, 19651990, Québec, Éditions de la Huit, 1991, p. 39-40.]

+ «L'agonie de Gérard", N'importe quelle route, vol. 2, n 1, avril 1988, p. 46. [Repris avec quelques variantes dans Hôtel Putama. Textes croisés, Longueuil-New York, 1965-1990, Québec, Éditions de la Huit, 1991, p. 21-23.]

+ "Un Noël, au motel “Diplomate" », N'importe quelle route, vol. 2, n 2, automne 1988, p. 26-27. [Repris avec quelques variantes dans Hôtel Putama. Textes croisés, Longueuil-New York, 19651990, Québec, Éditions de la Huit, 1991, p. 55-60.] 
+ "Victory et les stars du rodéo», N'importe quelle route, vol. 2, n 3, décembre 1988, p. 21.

[Repris avec quelques variantes dans Hôtel Putama. Textes croisés, Longueuil-New York, 19651990, Québec, Éditions de la Huit, 1991, p. 27-29.]

+ «La prostitution rue Champlain. Lettre ouverte à M. Yves Bellavance, directeur de La Criée», N'importe quelle route, vol. 3, nº 1, printemps 1989, p. 16.

+ «Junkies cow-boys», N'importe quelle route, vol. 3, no 1, printemps 1989, p. 23. [Repris avec quelques variantes dans Hôtel Putama. Textes croisés, Longueuil-New York, 1965-1990, Québec, Éditions de la Huit, 1991, p. 31-34.]

+ «Les Peter Jackson de l'Hôtel Putama. Pornographie, cocaïne et haute couture», N'importe quelle route, vol. 3, n 2, automne 1989, p. 26-27. [Repris avec quelques variantes dans Hôtel Putama. Textes croisés, Longueuil-New York, 1965-1990, Québec, Éditions de la Huit, 1991, p. 43-45.]

+ «Éditorial. La pollution plutôt que le silence», Espace global, no 12, juin 1994, p. 5-6.

\section{I.6.1. Poèmes dans des ouvrages collectifs}

+ «L'amour impérial», Luc Benoît, Paul Chamberland, Georges Khal et Jean Basile (dir.), Sortir, Montréal, L'Aurore, 1978, p. 269-272.

+ «Mark-ten», [Collectif], Atelier de production littéraire de la Mauricie 13. Pulsations, TroisRivières, Écrits des Forges, 1980, p. 10-11.

+ "Shampooing français», [Collectif], Atelier de production littéraire de la Mauricie 16. Décalques, Trois-Rivières, Écrits des Forges, 1982, p. 82-83.

+ «Codéine», [Collectif], Atelier de production littéraire de la Mauricie 17. Parler dans l'espace, Trois-Rivières, Écrits des Forges, 1982, p. 93-96.

+ «L'épilepsie de l'éteint», [Collectif], Québec kérouac blues, Trois-Rivières, Écrits des Forges, 1989, p. 110-112.

+ «Même mort, ils me tuent encore», [Collectif], Gaz Moutarde, Montréal, Éditions Espace Global, 1991.

+ "Préface» [ainsi que différents poèmes parus dans Steak haché], [Collectif], La vérité se passe un doigt. Steak haché anthologique, Trois-Pistoles, Éditions Trois-Pistoles, 2000.

\section{I.6.2. Poèmes dans des anthologies}

+ [Collectif], L'année poétique 1974, Paris, Seghers, 1975, p. 254-256.

+ [Collectif], Anthologie 80. Bilan et perspectives de la poésie franco-belge-québécoise, Talence (France)/Herstal (Belgique), Le Castor Astral/l'Atelier de l'agneau, 1981, p. 212-214.

+ [Collectif], Poètes québécois contemporains, Trois-Rivières, Écrits des Forges, 1987, p. 163-165.

+ Claude Beausoleil (dir.), Montréal est une ville de poèmes vous savez, Montréal, l'Hexagone, 1992, p. 105-107.

+ Louise Blouin et Bernard Pozier (dir.), Poètes québécois, Trois-Rivières, Écrits des Forges, 1993, p. 144-146.

+ Louise Blouin et Bernard Pozier (dir.), Poètes québécois, Trois-Rivières, Écrits des Forges/Orange bleue, 1996, p. 176-179.

+ Louise Blouin et Bernard Pozier (dir.), Anthologie. Poètes québécois, Trois-Rivières, Écrits des Forges, 1997, p. 144-146.

+ Louise Blouin et Bernard Pozier (dir.), Espace Québec. 65 poètes québécois, Trois-Rivières, Écrits des Forges, 2005, p. 282-286. 
+ Bernard Delvaille (dir.), Nouvelle poésie francophone, t. II, Paris, Seghers, 1977, p. 243-247.

+ Christian Descamps (dir.), Poésie du monde francophone, Talence (France), Le Castor Astral, 1986, p. 182.

+ Lucien Francoeur (dir.), 25 poètes québécois (1968-1978), Montréal, l'Hexagone, coll. «Anthologie», 1989, p. 167-178.

+ Réginald Hamel (dir.), Panorama de la littérature québécoise contemporaine, Québec, Guérin, 1997, p. 444-445.

+ Laurent Mailhot et Pierre Nepveu (dir.), La poésie québécoise. Anthologie, Québec, Presses de l'Université du Québec, 1981, p. 584-587; Montréal, l'Hexagone, 1986; Montréal, TYPO, 1996.

+ Jacques Rancourt (dir.), La poésie érotique du 20e siècle, [France], Éditions de la Pibole, 1980, p. 147-148.

+ Jacques Rivière (dir.), 101 poètes en Québec, Montréal, Guérin, coll. «Kébéca», 1995, p. 429430.

+ Jean Royer (dir.), La poésie québécoise contemporaine, Montréal/Paris, l'Hexagone/La Découverte, 1987, p. 148; 1991; 1995.

+ Frédéric-Jacques Temple (dir.), Québec vivant. Anthologie, Marseille, Sud, coll. «Domaine étranger», 1986, p. 209-211.

\section{7. Présences dans des ouvrages de référence}

+ [Collectif], Petit catalogue d'activités culturelles 74-75, Montréal, Atelier d'expression multidisciplinaire (ATEM), 1974, p. 62.

+ [Collectif], Rencontre internationale de la contre-culture, Montréal, Atelier d'expression multidisciplinaire (ATEM)/Bibliothèque nationale du Québec, 1975, p. 7, 15-17, 26.

+ [Collectif], Petit dictionnaire des écrivains, Montréal, Union des écrivains québécois, 1979, p. 174.

+ Roger Chamberland et Heinz Weinmann (dir.), Littérature québécoise, des origines à nos jours. Texte et méthode, Montréal, Hurtubise HMH, 1996, p. 168-169.

+ Gaëtan Dostie, Le solstice de la poésie québécoise, Montréal, Musée d'art contemporain de Montréal, 1977, p. 11, 33, 37 et 39.

+ Marc-Aimé Guérin et Réginald Hamel (dir.), Dictionnaire des poètes d'ici, Montréal, Guérin, 2001, p. 1018; Montréal, Guérin, 2005.

+ Réginald Hamel, John Hare et Paul Wyczynski (dir.), Dictionnaire des auteurs de langue française en Amérique du Nord, Montréal, Fides, 1989, p. 1327.

+ Ghislaine Houle et Jacques Lafontaine (dir.), Écrivains québécois de nouvelle culture, Montréal, Bibliothèque nationale du Québec, 1975, p. 111-119.

+ Yves Légaré (dir.), Dictionnaire des écrivains québécois (1970-1982), Montréal, Québec Amérique, 1983, p. 387.

+ William H. New (dir.), Encyclopedia of Literature in Canada, Toronto, University of Toronto Press, 2002, p. 1165.

+ Gordon Ripley et Anne Mercer (dir.), Who's Who in Canadian Literature 85-86, Toronto, Reference Press, 1985, p. 298-299. [Denis Vanier figure également dans des éditions subséquentes.]

+ Yves Robillard (dir.), Quebec Underground. Dix ans d'art marginal au Québec, 1962-1972, t. I, Montréal, Mediart, 1973, p. 157 et 455. 


\section{TRADUCTIONS DES EUVRES DE DENIS VANIER}

\section{I . 1. Livies}

+ The Clitoris of the Fairy of the Stars [Le clitoris de la fée des étoiles], traduction de Jack Hirshman, San Francisco, Golden Mount Press, 1976, [n. p.]. En anglais.

+ Louise Blouin et Bernard Pozier (dir.), Poetas de Quebec, Trois-Rivières/Mexico, Écrits des Forges/Editorial Aldus, 1996, p. 246-249. En espagnol.

+ Louise Blouin et Bernard Pozier (dir.), Esprit de corps. Quebec Poetry of the Late Twentieth Century in Translation, Trois-Rivières, Écrits des Forges, 1997, p. 115-116. En anglais.

+ Louise Blouin et Bernard Pozier (dir.), Poètes québécois/Poeti din Québec, Trois-Rivières, Écrits des Forges, 1997. En roumain.

+ Fulvio Caccia et John F. Deane (dir.), Voix d'Irlande et du Québec, Montréal/Dublin, Éditions du Noroît/Dedalus, 1995, p. 60-63 et 116-121. Traduction de l'anglais au français de Denis Vanier de poèmes de Ciaron O’Driscoll et version bilingue français-anglais de «Une Inca sauvage comme le feu ", traduit par Matthew Blake.

+ Titti Follieri (dir.), Antologia della poesia contemporanea del Québec, Milan, Crocetti Editore, 1998, p. 128-137. En version bilingue français-italien.

+ Hans-Jürgen Greif et François Ouellet (dir.), Literatur in Québec, Eine Anthologie/Littérature québécoise, une anthologie (1960-2000), traduction de Ingo Kolboom, Heidelberg (Allemagne), Wissenschaftsverlag der Autoren, 2000. En allemand.

\section{I. 2. En revues}

+ «French kiss», version bilingue français-anglais, traduction de Fraser Sutherland, Ellipse, $\mathrm{n}^{\circ}$ 17, 1975, p. 26-31.

+ «La maladie est en eux, ce sont des chiens», version bilingue français-anglais, traduction de Jack Hirshman, Amerus, an International Journal (San Francisco), nº 1, 1979.

+ "Acid lesbians», traduction de Barry Callaghan, Exile Quaterly (Toronto), vol. 10, n 1 , printemps 1985, p. 56-58. En anglais.

+ «Concept of the unrelativity of time», traduction de Marie-Évangeline Arsenault, Rampike (Toronto), vol. 7, n 2, 1991, p. 53.

+ «Déambule/Stroll», version bilingue français-anglais, traduction de Raymond Filip, Ellipse, $\mathrm{n}^{\circ} 56,1996$, p. 38-39.

+ « [extraits de Rejet de prince en version bilingue français-italien] », traduction de Titti Follieri, Poesia, no 112, décembre 1997, p. 55-56.

+ «Rock sucio» et «Armas par todos partes», traduction d'Arturo Parcho, Rimbaud (MexicoQuébec-Francia), nº 1, printemps 2006, p. 24. En espagnol.

\section{I I. P R I X E T D I S T I N C T IO N S}

+ Finaliste au Prix du Gouverneur général 1983 pour Rejet de prince.

+ Finaliste au Prix de poésie Terrasses Saint-Sulpice de la revue Estuaire 1991 pour Les stars du rodéo.

+ Prix de poésie Terrasses Saint-Sulpice de la revue Estuaire 1994 pour Le fond du désir.

+ Grand Prix du livre de Montréal 2000 pour L'urine des forêts (posthume).

+ En l'honneur de Denis Vanier, le Prix Langue-de-feu récompense annuellement, depuis 2001, un auteur et un illustrateur ayant participé à la revue Steak haché.

+ Le prix Denis-Vanier a été décerné au gala musical MIMI pour la qualité des textes en 2003-2004. 


\section{RÉ CEPTION C R ITIQUE}

\section{V.1.1. Mé mo i res}

+ FORTIN, Steve, «Denis Vanier à l'aune de la contre-culture», mémoire de maîtrise, Université d'Ottawa, 2004, $119 \mathrm{f}$.

+ LAMY, Jonathan, « Je est un autochtone. L'ensauvagement dans les poèmes de Paul-Marie Lapointe, Patrick Straram et Denis Vanier », mémoire de maîtrise, Université du Québec à Montréal, 2006, $110 \mathrm{f}$.

\section{V. 1 . 2. É tu des}

+ BEAUSOLEIL, Claude, «Le texte vaniérien», Cul-Q, nos 8-9, janvier 1976, p. 27-51.

+ BÉLANGER, Claude, «Pour baiser Vanier», La Barre du jour, n 38, hiver 1973, p. 63-79.

+ BISSONNETTE, Thierry, «Koréphilie et autres recueils de poésies de Denis Vanier et Josée Yvon », Aurélien Boivin (dir.), Dictionnaire des œuvres littéraires du Québec, t. VII (1981-1985), Montréal, Fides, 2003, p. 510-513.

+ CHAMBERLAND, Roger, «Je et Pornographic delicatessen», Maurice Lemire (dir.), Dictionnaire des œuvres littéraires du Québec, t. IV (1960-1969), Montréal, Fides, 1984, p. 455-458.

+ CHUNG, Yong, «Un prêtre sans cause» [principalement à propos de Renier son sang], Liberté, vol. 40, n³, juin 1998, p. 114-127.

+ FERLAND, Rémi, "Comme la peau d'un rosaire et autres recueils de poésies de Denis Vanier», Gilles Dorion (dir.), Dictionnaire des œuvres littéraires du Québec, t. VI (1976-1980), Montréal, Fides, 1994, p. 162-164.

+ FRÉCHETTE, Jean-Yves, «Lesbiennes d'acid et Le clitoris de la fée des étoiles», Maurice Lemire (dir.), Dictionnaire des œuvres littéraires du Québec, t. V (1970-1975), Montréal, Fides, 1987, p. 492-493.

+ RIVARD, Pierre, «Se situer, être perçu, définir, zoom on Denis Vanier et Josée Yvon », Dérives, $\mathrm{n}^{\circ} 1$, septembre-octobre 1975.

+ YERGEAU, Robert, "L'un des plus grands boursiers gouvernementaux », Art, argent, arrangement. Le mécénat d'État, Ottawa, Éditions David, 2004, p. 373-379.

\section{V. 1.3. Parties d'ouvrages}

+ BAYARD, Caroline, The New Poetics in Canada and Quebec, Toronto, University of Toronto Press, 1989, p. 180-182.

+ BEAUSOLEIL, Claude, «Explorer l'éclatement», Les livres parlent, Trois-Rivières, Écrits des Forges, 1984, p. 214-215.

+ BEAUSOLEIL, Claude, Extase et déchirure, Trois-Rivières/Cesson-La-Forêt (France), Écrits des Forges/La Table rase, 1987, p. 70-71.

+ BEAUSOLEIL, Claude, Le motif de l'identité dans la poésie québécoise, Montréal, Estuaire, coll. «Essai», 1999, p. 42-44.

+ BOURASSA, André-G., Surréalisme et littérature québécoise, Montréal, Éditions L'Étincelle, 1977, p. 268-272; Montréal, TYPO, 1986, p. 478-485.

+ GAUDET, Gérald, "L'Lacquise faute de l'âme" ", Les Écrits des Forges. Une poésie en devenir, Trois-Rivières, Écrits des Forges, 1983, p. 35-37.

+ HÉBERT, François, Pour orienter les flèches. Notes sur la guerre, la langue et la forêt, Montréal, Trait d'union, 2002, p. 14 et 68-71.

+ MAILHOT, Laurent, La littérature québécoise, Paris, Presses universitaires de France, coll. «Que sais-je?», 1974, p. 82-83. 
+ MAILHOT, Laurent, La littérature québécoise, Montréal, TYPO, 1997, p. 126 et 195.

+ ROYER, Jean, Introduction à la poésie québécoise, Montréal, Bibliothèque québécoise, 1989, p. 109.

\section{IV.1.4. Commentaires parus dans des périodiques}

+ BEAUSOLEIL, Claude, "Hypothèses», Dérives, no 8, janvier 1977, p. 16-28 [v. p. 19-20, 25-26].

+ BEAUSOLEIL, Claude, "La poésie en revue depuis 10 ans», La Petite Revue de philosophie, vol. 4, no 1, automne 1982, [p. 117].

+ BOURASSA, André-G., "Chaîne et trame. Rina Lasnier, Denis Vanier et Josée Yvon », Lettres québécoises, nº 5, février 1977, p. 11-13.

+ BRASSARD, Denise, «La contre-culture en poésie. Un passage étroit», Lectures, vol. 2, no 11 , août 1995, p. 7.

+ DESMEULES, Louis, «La vie sociale des mots de Nelligan et de Vanier», Possibles, vol. 18, n 4 , automne 1994, p. 79-87.

+ DONTIGNY, Aimé, «Ce poète dont nul ne parle», La Conspiration dépressionniste, n 1 , printemps-été 2003. [Texte en ligne à http://consdep.hopto.org/vanier.html (site consulté en septembre 2006).]

+ FOLLIERI, Titti, «Otto poeti contemporanei del Québec», Poesia, nº 112, décembre 1997, p. 47-54 [v. p. 51].

+ GERMAIN, Renaud, «Mind fuck in the frame/Baise mentale dans le cadrage», Kerozen magazine, $\mathrm{n}^{\circ} 22$, printemps 2000, p. 25.

+ IMBEAULT, Jean, «Bribe(s)», Frayages, n 1, «La psychanalyse est-elle mortelle?», 1984, p. 91-123 [v. p. 118-121]. [Commentaire-fiction autour de Lesbiennes d'acid.]

+ MICHON, Jacques, «Surréalisme et modernité», Études françaises, vol. 11, nº 2, mai 1975, p. 121-129 [v. p. 123].

+ ROBERT, Guy, «La poésie sauvage au Québec», Revue d'esthétique, nos 3-4, «Il y a des poètes partout», 1975, p. 132-163 [v. p. 153].

+ STRARAM, Patrick, le Bison ravi, "Lettre personnelle à Michel Beaulieu », Le Livre d'ici, vol. 6, no 14,7 janvier 1981.

+ TREMBLAY, Tony, «L'Association des poètes du Québec prend sa place», Lectures, vol. 2, nº 8 , avril 1995, p. 5.

+ YERGEAU, Robert, "Évolution du discours sur la poésie au journal Le Devoir (1950-1980)", Mœbius, no 17, printemps 1983, p. 59-85 [v. p. 67-70, 83-84].

\section{IV.2. Comptes rendus}

\section{V.2.1. Je}

+ BEAUSOLEIL, Claude, «Lire aujourd'hui. Je», Hobo-Québec, nos 23-24, janvier-avril 1975, p. 11.

+ LEMIEUX, Jacques, «Je est un coup de foudre», Le Devoir, 14 décembre 1974, p. 15.

+ MAJOR, André, "Trois jeunes poètes», Livres et auteurs canadiens 1965, Montréal, Éditions Jumonville, 1966, p. 97.

+ SYLVESTRE, Guy, «La poésie. Délire contre délire», Le Devoir, 24 juillet 1965, p. 8.

\section{IV.2.2. Pornographic delicatessen}

+ MARTEL, Réginald, "Poètes de l'amour et du pays. Pornographic delicatessen », La Presse, 15 mars 1969, p. 34. 
+ PILON, Jean-Guy, "Vers une nouvelle sensibilité? Quand la poésie veut se suicider», Le Devoir, 8 mars 1969, p. 21.

+ THÉBERGE, Jean-Yves, «Nicole Brossard et Denis Vanier», Le Canada français, 2 avril 1969, p. 36.

\section{IV.2.3. Lesbiennes d'acid}

+ BASILE, Jean, «Lesbiennes d'acid», Mainmise, n 17, novembre 1972, p. 14-16.

+ BEAULIEU, Victor-Lévy, "La parole nouvelle, criée par les prophètes du planétaire », Le Devoir, 23 décembre 1972, p. 13-14. Repris dans Chroniques du pays malaisé, Trois-Pistoles, Éditions Trois-Pistoles, 1996, p. 113-118.

+ BOLDUC, Yves, «Lesbiennes d'acid», Livres et auteurs québécois 1972, Montréal, Éditions Jumonville, 1973, p. 160-161.

+ CHARRON, François, «Violence, répercussion», Presqu'Amérique, vol. 1, n 10, octobrenovembre 1972, p. 22-24.

+ KRAVETZ, Marc, «Lesbiennes d'acid», Magazine littéraire, no 140, septembre 1978, p. 33.

+ LÉVESQUE, Robert, «Chez les "parallèles” de la littérature québécoise, un dénominateur: la poésie», Québec-Presse, 24 décembre 1972, p. 22.

+ MARTEL, Réginald, «Poésie d'ici. Denis Vanier», La Presse, 7 octobre 1972, p. D3.

+ PIAZZA, François, «Les écorchés... », Montréal-Matin, $1^{\text {er }}$ octobre 1972, p. 19.

+ PILON, Jean-Guy, «Denis Vanier, poète révolutionnaire», Le Devoir, 9 février 1973, p. 15.

+ THÉBERGE, Jean-Yves, «Un bout de l'existence de Denis Vanier», Le Canada français, 18 octobre 1972, p. 106.

\section{IV.2.4. Le clitoris de la fée des étoiles}

+ BEAUSOLEIL, Claude, "Lire aujourd'hui. Le clitoris de la fée des étoiles», Hobo-Québec, nº 19, septembre-octobre 1974, p. 23.

+ BOURASSA, André-G., «Prolongements du surréalisme. Aux lèvres de Vanier», Livres et auteurs québécois 1974, Sainte-Foy, Les Presses de l'Université Laval, 1975, p. 368-370.

+ DOSTIE, Gaétan, «Petit bilan de la poésie», Le Jour, 28 décembre 1974.

+ DUMOUCHEL, Thérèse, "À Germain - entre la dépense improductive et le fascisme», Chroniques, vol. 1, nº 1, janvier 1975, p. 74-79 [v. p. 76-79].

+ HAECK, Philippe, «Le clitoris de la fée des étoiles», Chroniques, vol. 1, nº 1, janvier 1975, p. 81.

+ LÉGER, Pierre (Pierrot-le-fou), «Denis Vanier, ou la solitude littéraire», Mainmise, n 33, mars 1974, p. 3.

+ LEMIEUX, Jacques, «Petit bilan. Éditions québécoises et Herbes rouges», Le Devoir, 31 août 1974, p. $12-13$.

+ MARTEL, Réginald, «Poésie d'ici. Denis Vanier», La Presse, 29 juillet 1974, p. D2.

\section{IV.2.5. Comme la peau d'un rosaire}

+ BEAUSOLEIL, Claude, «Les livres parlent. Comme la peau d'un rosaire», Mainmise, nº 72, 1977, p. 41.

+ BEAUSOLEIL, Claude, «Livres. Comme la peau d'un rosaire», Québec Rock, vol. 1, nº 7 , octobre 1977, p. 36.

+ BOURASSA, André-G., «Poésie et communication - en forme de journal et d'examen [...] de conscience», Lettres québécoises, n 8, novembre 1977, p. 12-14. 
+ CIMON, Renée, "Comme la peau d'un rosaire», Nos livres, nº 118, mars 1979.

+ DAGENAIS, Angèle, «Vient de paraître», Le Devoir, 11 octobre 1977, p. 15.

+ GAULIN, André, "Comme la peau d'un rosaire», Québec français, décembre 1977, p. 6.

+ HÉBERT, François, «Lefrançois, Beaulieu, Nepveu, Vanier», Liberté, nº 114, novembredécembre 1977, p. 93-99 [v. p. 98-99].

+ RENAUD, Jacques, «Douze poètes québécois. Les bons sentiments ne font pas la poésie... les mauvais non plus», Le Devoir, 22 octobre 1977, p. 34.

+ ROYER, Jean, «Comme la peau d'un rosaire», Le Devoir, 21 juillet 1978, p. 8.

\section{V.2.6. L'odeur d'un athlète}

+ BOURASSA, André-G., «Entre l'espace et le temps», Lettres québécoises, n 14, avril-mai 1979, p. 18-21 [v. p. 20].

\section{IV.2.7. Euvres poétiques complètes}

+ BAYARD, Caroline, "Poésie», University of Toronto Quaterly, vol. 50, n 4, été 1981, p. 41-54 [v. p. 52].

+ BEAUliEU, Ivanhoé, «Denis Vanier, pas si maudit qu'on le dit», La Presse, 17 janvier 1981, p. C2.

+ BEAUliEU, Michel, «Qui a peur de Denis Vanier?», Le Livre d'ici, vol. 6, nº 15, 14 janvier 1981.

+ CORRIVEAU, Hugues, "Denis Vanier, Euvres poétiques complètes», Livres et auteurs québécois 1980, Sainte-Foy, Les Presses de l'Université Laval, 1981, p. 137-140.

+ GILBERT, Bernard, «Euvres poétiques complètes, t. I», Bulletin Pantoute, avril-juin 1981, p. 15.

+ LAMARRE, André, "Révolte jusqu'à l'honneur», Spirale, no 16, février 1981, p. 8.

+ NEPVEU, Pierre, «L'écriture à la première personne, Vanier et Beausoleil», Lettres québécoises, no 21, printemps 1981, p. 26-28.

+ POZIER, Bernard, «Les poèmes de Denis Vanier», Le Nouvelliste, 3 janvier 1981, p. 14.

+ ROBitAiLlE, Claude, «EFuvres poétiques complètes de Denis Vanier», Le Berdache, no 19, avril 1981, p. 49.

+ ROBITAILLE, Claude, «Les Eruvres poétiques complètes, t. I de Denis Vanier. Un événement en “soie"», Estuaire, no 19, printemps 1981, p. 107-109.

\section{V.2.8. Koréphilie}

+ BEAULIEU, Ivanhoé, "Trop heavy de tendresse», La Presse, 23 janvier 1982, p. C3.

+ BEAULIEU, Michel, «Elle et lui», Le Livre d'ici, vol. 7, nº 19, 10 février 1982.

+ BEAUSOLEIL, Claude, "La poésie revue depuis dix ans», La Petite Revue de philosophie, automne 1982, p. 117.

+ BROCHU, André, «En état de poésie», Voix et Images, vol. 8, n 1, automne 1982, p. 159-167 [v. p. 160-161]. Repris dans Tableau du poème, Montréal, XYZ éditeur, coll. «Documents», 1994, p. 107-108.

+ DÉRY, Pierre-Justin, «Le corps transgressif», Livres et auteurs québécois 1981, Sainte-Foy, Les Presses de l'Université Laval, 1982, p. 142-143.

+ DESGENT, Jean-Marc, "Koréphilie», Le Berdache, n 28, mars 1982, p. 54-55.

+ DIONNE, André, «Koréphilie», Nos livres, nº 312, juin-juillet 1982.

+ DIONNE, André, «Koréphilie», Lettres québécoises, n 28, hiver 1982-1983, p. 80.

+ POZIER, Bernard, «Se travestir pour survivre», Le Nouvelliste, 14 novembre 1981, p. 18. 


\section{IV.2.9. Rejet de prince}

+ BROCHU, André, «Écriture en locomobile», Voix et Images, vol. 10, no 1, automne 1984,

p. 151-162. Repris dans Tableau du poème, Montréal, XYZ éditeur, coll. «Documents», 1994, p. 108-109.

+ CHAMBERLAND, Roger, "Les mains libres. Rejet de prince», Québec français, mai 1984, p. 9.

+ D'ALFONSO, Antonio, "Rejet de prince», Nos livres, mai 1984, p. 36.

+ JEANDRÉ, «Des lèvres aux canons», Sortie, nº 16, avril 1984, p. 24.

+ MALENFANT, Paul Chanel, «Rejet de prince», Nuit blanche, nº 14, juin-juillet-août 1984, p. 6.

+ MARTIN, Marie-Agnès, "La poésie du désir», The Link, mars 1984, p. 9.

+ NEPVEU, Pierre, «Écriture-tatouage et langage raréfié», Le Devoir, 31 mars 1984, p. 22.

+ OLSCAMP, Marcel, «La poésie interdite», La poésie au Québec (revue critique 1990), TroisRivières, Écrits des Forges, 1991, p. 136-137.

+ TOUPIN, Gilles, «Denis Vanier, le poète iconoclaste», La Presse, 14 avril 1984, p. D2.

+ YERGEAU, Robert, «La poésie dans tous ses états. Langevin, Vanier, Geoffroy, van Schendel, Cloutier», Lettres québécoises, no 34, été 1984, p. 30-34 [v. p. 31-32].

+ YERGEAU, Robert, «Poésie. Mêler les styles... et autres errances», University of Toronto Quarterly, été 1985, p. 363-375 [v. p. 374].

\section{V.2 . 10. L'âme/défigurée}

+ [Anonyme], «Couple d'artistes», Mensuel 25 (Belgique), nos 93-94, mars 1985, p. 50-54.

+ CARRIÈRE, Daniel, «L'âme défigurée», Sortie, n²5, février 1985, p. 22.

+ CARRIÈRE, Daniel, «Crimes et tactiques», Lettres québécoises, n 39, automne 1985, p. 54-55.

\section{IV.2.11. Cette langue dont nul ne parle}

+ BEAUDOIN, Réjean, «Les mouches du plafond», Liberté, juin 1986, p. 126-131 [v. p. 127].

+ CAMPBELL, Jocelyne Ann, "Denis Vanier récidive avec un nouveau recueil de poèmes», La Criée, 5 juin 1985, p. 8.

+ CARRIĖRE, Daniel, «Crimes et tactiques», Lettres québécoises, n 39, automne 1985, p. 54-55.

+ NEPVEU, Pierre, «Quelques voyages dans le réel», Spirale, no 56, novembre 1985, p. 3.

+ ROYER, Jean, «Chronique pour non-liseurs de poésie. Le poète et son personnage», Le Devoir, 31 mai 1986, p. C4.

+ TOUPIN, Gilles, «Vanier et la langue de l'amour», La Presse, 19 octobre 1985, p. D3.

+ TRUDEL, Serge, «Cette langue dont nul ne parle», Nos livres, novembre-décembre 1985, p. 32-33.

\section{IV.2.12. Travaux pratiques}

+ BASILE, Jean, «Josée Yvon et Denis Vanier critiques», La Presse, 31 octobre 1987, p. J7.

+ FERLAND, Rémi, «De la délicatesse qui saigne. Les commandos du désespoir », N'importe quelle route, vol. 1, nº 3, octobre 1987, p. 37-39. [Préface du livre.]

+ LAMY, Jonathan, "Travaux pratiques de Denis Vanier et Josée Yvon », Aurélien Boivin (dir.), Dictionnaire des œuvres littéraires du Québec, t. VIII (1986-1990), Montréal, Fides, à paraître en 2008.

\section{IV.2.13. L'épilepsie de l'éteint}

+ POPOVIC, Pierre, «Supporte et ne t’abstiens pas», Spirale, n 83, novembre 1988, p. 4.

+ TOUPIN, Gilles, «Visages de la passion», La Presse, 3 décembre 1988, p. K3. 


\section{V.2.14. Les stars du rodéo}

+ BIRON, Michel, «L'œil du poète», Spirale, no 105, avril 1991, p. 11.

+ CLOUTIER, Guy, "Les stars du rodéo», Le Soleil, 2 mars 1992, p. A10.

+ FELX, Jocelyne, "Glissements vers l'enfance», Lettres québécoises, no 59, automne 1990, p. 35-36.

+ MALENFANT, Paul Chanel, «Dans les chances de la poésie», Voix et Images, vol. 16, nº 1 (46), automne 1990, p. 176-192.

+ TOUPIN, Gilles, «Oh! les beaux textes», La Presse, 18 novembre 1990, p. C7.

\section{IV.2.15. Hôtel Putama}

+ BASILE, Jean, «Réminiscences de l'underground d'autrefois», Le Devoir, 30 mars 1991, p. D3.

+ CÔTÉ, Lucie, "Curieux séjour», La Presse, 9 juin 1991, p. C3.

\section{IV.2.16. Une Inca sauvage comme le feu}

+ CÔTÉ, Gilles, «Une Inca sauvage comme le feu», Nuit blanche, n 51, printemps 1993, p. 18.

+ FORTIN, Marie-Claude, «Vient de paraître», Voir, 24 septembre 1992, p. 32.

+ TOUPIN, Gilles, «La naissance du poème», La Presse, 18 octobre 1992, p. B5.

\section{IV.2.17. L'hôtel brûlé}

+ CAYOUETTE, Pierre, «Le plaisir de l'un, c'est de voir l'autre...», Le Devoir, 16 octobre 1993, p. D7.

+ CLOUTIER, Cécile, «Poésie 1993-1994», University of Toronto Quarterly, vol. 65, nº 1, hiver 1995/1996, p. 76-100 [v. p. 80].

+ COPPENS, Patrick, "L’hôtel brûlé», La littérature québécoise 1993, Montréal, Services documentaires multimédia, juillet 1994, p. 24.

+ LAURIN, Danielle, «L'avaleur de feu», Voir, 14 octobre 1993, p. 41.

+ PERRON, Jean, "Un humaniste», La poésie au Québec (revue critique 1990), Trois-Rivières, Écrits des Forges, 1996, p. 138-143.

+ RICHARD, Christine "L'hôtel brûlé», Lectures, vol. 1, n 1, septembre 1993, p. 12.

+ TOUPIN, Gilles, «Offrir son corps à la poésie», La Presse, 26 septembre 1993, p. B6.

\section{V.2.18. Le fond du désir}

+ BRASSARD, Denise, "Le fond du désir», Lectures, vol. 2, n 6, février 1995, p. 21.

+ CLOUTIER, Cécile, «Poésie 1993-1994», University of Toronto Quarterly, vol. 65, nº 1, hiver 1995/1996, p. 76-100 [v. p. 91].

+ COPPENS, Patrick, «Le fond du désir », La littérature québécoise 1994, Montréal, Services documentaires multimédia, octobre 1995, p. 4.

+ CORRIVEAU, Hugues, "Au coin de la rue, le désir», Lettres québécoises, n 78, été 1995, p. 44.

+ LONGCHAMPS, Renaud, «Six poètes sur la route 666 », Nuit blanche, n 59, mars-mai 1995, p. 50-52.

\section{IV.2.19. Renier son sang}

+ BERTIN, Raymond, «Renier son sang», Voir, 23 mai 1996, p. 35.

+ CANTIN, David, «Dans le désordre de la réalité», Le Devoir, 25 mai 1996, p. D5.

+ CHAMBERLAND, Roger, "Renier son sang», Québec français, n 104, hiver 1997, p. 10.

+ CHAMBERLAND, Roger, "Poésie», University of Toronto Quarterly, vol. 67, hiver 1997/1998, p. 375-390 [v. p. 384]. 
+ COPPENS, Patrick, «Renier son sang», La littérature québécoise 1996, Montréal, Services documentaires multimédia, mai 1997, p. 6.

+ GAGNIER, Maurice, «Renier son sang», Le Sabord, n 44, automne 1996, p. 38.

\section{V.2.20. La castration d'Elvis}

+ BERTIN, Raymond, «La castration d'Elvis», Voir, $1^{\mathrm{er}}$ mai 1997, p. 41.

+ BISSONNETTE, Thierry, "La castration d'Elvis», Nuit blanche, nº 70, printemps 1998, p. 19.

+ CANTIN, David, «Écrire en marge», Le Devoir, 7 juin 1997, p. D4.

+ CARDUCCI, Lisa, «La castration d’Elvis», Envol, vol. VI, n 1, 1998, p. 81-82.

+ CHAMBERLAND, Roger, «Poésie», University of Toronto Quaterly, vol. 68, hiver 1998/1999, p. 38-59 [v. p. 54].

+ COPPENS, Patrick, «La castration d'Elvis», La littérature québécoise 1997, Montréal, Services documentaires multimédia, mai 1998, p. 5.

+ CORRIVEAU, Hugues, «La certitude d'habiter ailleurs que dans ma bouche», Lettres québécoises, nº 87, automne 1997, p. 47.

\section{IV.2.21 Noyée dans le bain avec son chat}

+ RICARD, Karen, «Noyée dans le bain avec son chat», Ici, 9 avril 1998, p. 20.

\section{IV.2.22. Tu me trompes avec un oiseau}

+ BERTIN, Raymond, «Tu me trompes avec un oiseau», Voir, 11 juin 1998, p. 39.

+ CANTIN, David, «Imaginaires baroques», Le Devoir, 16 mai 1998, p. D2.

+ CHAMBERLAND, Roger, «Un mal de vivre profond», Québec français, n 111, automne 1998, p. 10.

+ CHAMBERLAND, Roger, «Poésie», University of Toronto Quarterly, vol. 69, hiver 1999/2000, p. 401-418 [v. p. 410-411].

+ MUIR, Michel, «Tu me trompes avec un oiseau», Envol, vol. VII, n 1, 1999, p. 66-68.

\section{IV.2.23. Le baptême de Judas}

+ CHAMBERLAND, Roger, «Poésie», University of Toronto Quarterly, vol. 69, hiver 1999/2000, p. 401-418 [v. p. 411].

+ CORRIVEAU, Hugues, «Ent'deux joints», Lettres québécoises, no 96, hiver 1999, p. 36-37.

\section{IV.2.24. L'urine des forêts}

+ CHAMBERLAND, Roger, «Poésie», University of Toronto Quarterly, vol. 70, hiver 2000/2001, p. $39-58$ [v. p. 47].

+ GRANGER, Alice, «Ā propos de L'urine des forêts », Exigence: Littérature, http://www.elitterature.net/oeuvre/auteurs.php (site consulté en septembre 2006).

+ PETERSON, Michel, «L'urine des forêts», Nuit blanche, nº 79, été 2000, p. 14.

\section{IV.2.25. Porter plainte au criminel}

+ BEAUSOLEIL, Claude, "Porter plainte au criminel», Europe, n 870, octobre 2001, p. 331-332.

+ CANTIN, David, «La dernière strophe», Le Devoir, 4 août 2001, p. D4.

+ CHAMBERLAND, Roger, "Porter plainte au criminel», Québec français, n 123, automne 2001.

+ CORRIVEAU, Hugues, «Penser vivre», Lettres québécoises, n 104, hiver 2001, p. 45-46. 


\section{V. 3. Entrevu es}

+ [Anonyme], «Denis Vanier... le saccage de tous les tabous», Le Journal de Montréal, 10 juillet 1974, p. 25.

+ BAILLARGEON, Normand, «Denis Vanier, le poète de la souffrance», Le Devoir, 15 octobre 1996, p. B1. Repris dans Trames. Esthétique/Politique, Québec, Nota bene, coll. «Interventions», 2004, p. 60-69.

+ BERTIN, Raymond, «Denis Vanier. À feu et à sang», Voir, 2 février 1995, p. 33.

+ DEMERS, Pierre, «Entrevue avec Denis Vanier», http://www.cocagne.org/bum/entrevue.htm (site consulté en avril 2006).

+ DESJARDINS, Marc, «Interview (duo-poème) de Josée Yvon et Denis Vanier », Mainmise, n 48 , 1974, p. 24-26.

+ DESPATIE, Stéphane, «Denis Vanier, le dernier poète maudit», La Presse, 17 septembre 2000, p. C1.

+ DIONNE, André, «Denis Vanier, poète», Lettres québécoises, n 21, printemps 1981, p. 47-51.

+ GRAVENOR, Kristian, «The Great Biker War», Mirror, 4 mai 1995, p. 10-12. [Une photographie de Denis Vanier se trouve en couverture du journal.]

+ LAURIN, Danielle, «Saint-Vanier de-la-Croix», Le Devoir, 8 avril 1995, p. D5.

+ LEEGER, Pierre (Pierrot-le-fou), «La sensation d'être un hors-la-loi», Magazine Maclean, vol. 7, décembre 1967, p. 38-39.

+ MARTEL, Réginald, «Un poète canadien chez les Beatles», La Presse, 29 mars 1969, p. 22.

+ MARTIN, Jean-Guy, "Gauvreau, le premier à me montrer un certain esprit de liberté"», Le Journal de Montréal, 28 février 1981, p. 8.

+ MARTIN, Jean-Guy, «Écrire un poème... », Le Journal de Montréal, 20 février 1982, p. 56.

+ RABY, Georges, «La poésie se fait objet de consommation», Perspectives, vol. 12, n 5 , 31 janvier 1970, p. 2-4. [Décrit l'ambitieux projet de publication «Mustard Darling» qui avortera et sera renommé Lesbiennes d'acid.]

+ ROYER, Jean, «Denis Vanier, langue de feu», Le Devoir, 4 avril 1981, p. 26.

+ SOULIÉ, Jean-Paul, «Denis Vanier. Pour ne pas mourir d'amour», La Presse, 12 mai 1984, p. D1-D2.

+ SZUCSANY, Désirée, «La terrible lucidité de Josée Yvon", Le Devoir, 14 juin 1994, p. B7. [Sur la mort de Josée Yvon.]

+ TRAIT, Jean-Claude, «En pleine période rose, Denis Vanier travaille à deux », La Presse, 17 août 1974, p. E2.

+ YVON, Josée, «Denis Vanier, poète offert à la chasse», Sortie, nº 10, septembre 1983, p. 13-14.

\section{IV.4.1. Articles de journaux}

+ [Anonyme], «Vanier lu par Jenny Rock», Montréal-Matin, 13 janvier 1976, p. 18.

+ [Anonyme], "Arrestation du poète Denis Vanier», Le Temple, la revue du grand Québec, mai 1980, p. 23.

+ [Anonyme], «Denis Vanier est honoré», La Presse, 26 février 1995, p. B4.

+ [Anonyme], «Un prix posthume pour Vanier», Le Droit, 14 novembre 2000, p. 36.

+ [Anonyme], «Un prix posthume pour le poète Denis Vanier», Le Soleil, 14 novembre 2000, p. E14.

+ [Anonyme], «Hommage à Denis Vanier (1949-2000)», Inter-Loge Express, vol. 8, n 4, septembre 2002, p. 2. 
+ BARBERIS, Robert, «Les contre-culturistes», Le Jour, 26 avril 1975.

+ BEMCHINSKY, Bryan, «Bad boy of poetry honoured after death», The Gazette, 14 novembre 2000, p. F7.

+ GAUVREAU, Claude, "Gauvreau présente Vanier», Le Devoir, 30 octobre 1971, p. 32. [Annoncé comme la préface de Lesbiennes d'acid, ce texte est en fait la préface de Je.]

+ GRAVENOR, Kristian, "Our city's book scam», Mirror, 16 novembre 2000.

+ LEPAGE, Jocelyne, «Denis Vanier, Grand Prix du livre de Montréal», La Presse, 14 novembre 2000, p. C5.

+ MARTEL, Réginald, "Un mot de Paul Chamberland», La Presse, 2 mai 1985, p. A9. [Sur une lettre conjointement écrite par Paul Chamberland, Denis Vanier et Josée Yvon à propos du vol de la discothèque de Patrick Straram.]

+ MONTPETIT, Caroline, «L'incandescence a une ville. Denis Vanier reçoit le Grand prix du livre de Montréal», Le Devoir, 14 novembre 2000, p. B8.

+ MONTPETIT, Caroline, «Denis Vanier réincarné», Le Devoir, 12 mai 2001, p. B10.

+ NAVARRO, Pascale, "Solo Vox [sic] consacre une soirée à Denis Vanier», Voir, 21 septembre 2000, p. 48.

+ PAQUIN, Éric, «Grand Prix du livre de Montréal 2000 », Voir, 16 novembre 2000, p. 58.

+ ROGER, Éric, «L'univers poétique du Steak haché», Quartier libre, 11 janvier 2000, p. 17.

+ ROYER, Jean, «Vanier boursier», Le Devoir, 23 mars 1985, p. 22.

+ SARRAZIN, Guy, "Alerte générale», Le Devoir, 12 avril 1980, p. 28. [Sur l'arrestation de Denis Vanier lors de la Nuit de la poésie 1980.]

+ TREMBLAY, Jacques, "Ā quoi ça rime ce "Ā quoi ça rime" ?", Le Devoir, 12 août 1974, p. 4.

\section{IV.4.2. Autour de la mort de Denis Vanier}

+ [Anonyme], «Mort d'un poète», Le Droit, 11 octobre 2000, p. 36.

+ [Anonyme], «Mort du poète Denis Vanier», Le Journal de Montréal, 11 octobre 2000.

+ [Anonyme], «Poet Vanier dies at 51 », The Gazette, 11 octobre 2000, p. F7.

+ [Anonyme], «Denis Vanier», Ici, 12 octobre 2000, p. 5.

+ ASSELIN, Suzanne, «Hommage posthume à Denis Vanier», Montréalités, vol. 19, nº 8 , décembre 2000, p. 8.

+ BAILlARGEON, Stéphane, "Mort du poète de la révolte», Le Devoir, 10 octobre 2000, p. B7.

+ FOGLIA, Pierre, «Un autre monstre», La Presse, 19 décembre 2000, p. A5.

+ HÉBERT, François, «Tatouer le ciel d'octobre», Le Devoir, 12 octobre 2000, p. A8. Repris dans Pour orienter les flèches. Notes sur la guerre, la langue et la forêt, Montréal, Trait d'union, 2002, p. 14.

+ LAMY, Jonathan, «Astheure qu'y est mort, lisez donc Denis Vanier», Main blanche, vol. 7, no 3, décembre 2000, p. 12.

+ LEPAGE, Jocelyne, «Denis Vanier, le dernier poète maudit, est mort», La Presse, 11 octobre 2000, p. C3.

+ MALAVOY-RACINE, Tristan, «Denis Vanier (1949-2000)», Voir, 12 octobre 2000, p. 4.

+ PETROWSKI, Nathalie, «Le respect des morts», La Presse, 12 octobre 2000, p. C3.

+ ROGER, Éric, «Les derniers fruits de la terre», Le Manoir des poètes, été-automne 2001, p. 15.

\section{IV.5. Présences dans des œuvres de fiction}

+ BRISEBOIS, Patrick, Trépanés, Montréal, L'effet pourpre, p. 87-89. [Description d'une bataille au Festival international de poésie de Trois-Rivières mettant en vedette Denis Vanier.] 
+ MASSIE, Jean-Marc, La dernière tentation du lys, Montréal, Planète rebelle, 1999, p. 57-68 et 105-106. [Citations de Denis Vanier intégrées au texte.]

+ FONTAINE, Violette et Pierre L'HERBIER, Anthologie apocryphe de la poésie québécoise du XXe siècle, Montréal, Varia, 2005, p. 85. [Pastiche d'un poème de Denis Vanier.]

+ FRANCOEUR, Lucien, «Les nourritures terrestres», Rampike, 1986, p. 59. [Poème presque entièrement composé de titres de livres de Denis Vanier et de Josée Yvon.]

\section{IV.6. B a ndes dessinées}

+ "La fiction de son intimité», dessin de Richard Suicide, Espace global, n 5, été 1993, p. 18.

+ «Étrange bacon», scénario de Denis Vanitos [Denis Vanier] et dessins de DJBitos [Guy Boutin], Wah comix, nº 7, [Montréal], [2002 ?].

+ «Texte de police» [de Comme la peau d'un rosaire], dessins et lettrage de Guy Boutin, Wah comix, no 7, [Montréal], [2002 ?].

+ «Le brûle-parfum» [de Hôtel Putama], dessins et lettrage de Guy Boutin, Wah comix, n 8 , [Montréal], [2003 ?].

\section{F I L M O G R A P H I E}

V.1.1. Films sur Denis Vanier

+ BINAMÉ, Charles, Denis Vanier présente son show de monstre, Montréal, Radio-Québec, série «La vie qu'on mène», 1974, 60 min. [Scénario de Denis Vanier et Josée Yvon.]

+ GAGNÉ, Jean et Serge GAGNÉ, Ton père est un bum, Montréal, Cinéma libre/Les Productions Cogagne/Le Vidéographe, 1997, 83 min.

\section{V.1.2. Films dans lesquels Denis Vanier apparaît}

+ CHOUINARD, Denis, Le verbe incendié, Montréal, Synercom Téléproductions/INRS-Culture et Société, Télé-Québec, série «La culture dans tous ses états», 1999, 52 min.

+ CYR, Luc et Carl LEBLANC, Archives de l'âme, Montréal, Ad Hoc Films/Télé-Québec, série «24 heures pour l'histoire», 2001, 61 min. [Documentaire sur «La nuit de la poésie».]

+ GAGNÉ, Jean et Serge GAGNÉ, Une semaine dans la vie des camarades, Montréal, Atelier d'expression multidisciplinaire/Productions 89, 1975, 240 min.

+ LABRECQUE, Jean-Claude et Jean-Pierre MASSE, La nuit de la poésie, Montréal, Office national du film du Canada, 1970, $111 \mathrm{~min}$.

+ LABRECQUE, Jean-Claude et Jean-Pierre MASSE, La nuit de la poésie 1980, Montréal, Office national du film du Canada, 1980, 115 min.

+ LABRECQUE, Jean-Claude et Jean-Pierre MASSE, La nuit de la poésie 1991, Montréal, Service de l'audio-visuel de l'Université du Québec à Montréal/Films de la Traîne Sauvage/Conifère Têtu, 1991, 58 min.

\section{V.2.1. À propos de Denis Vanier présente son show de monstre}

+ GAY, Richard, «Tana, Brault, Binamé», Le Devoir, 26 avril 1980, p. 27.

+ TADROS, Jean-Pierre, "Vallières, Vanier et les paysans du Larzac», Le Jour, 22 octobre 1975.

+ VILLEMAIRE, Yolande, "Show-time. La vie qu'on mène», Hobo-Québec, nos 21-22, janvieravril 1975, p. 17. 


\section{V.2.2. À propos de Ton père est un bum}

+ DEMERS, Pierre, «Ton père est un bum ou le poète encerclé » et «Entrevue avec les frères Gagné», http://www.cocagne.org/bum/entrevue.htm (site consulté en avril 2006).

+ FOURLANTY, Éric, "Ton père est un bum», Voir, 28 mai 1998, p. 36.

+ LUSSIER, Marc-André, "Ton père est un bum. La poésie survoltée de Denis Vanier», La Presse, samedi 30 mai 1998, p. C7.

+ PELLETIER, Denise, «"La poésie à l'ouvrage". Deux cinéastes filment des poètes», Le Quotidien, 22 octobre 1997, p. 42.

\section{I. D I S C O G R A P H I E}

+ BELLIARD, Alexandre, "La star du rodéo», Piège à con, Montréal, Musicor, 2005. [Le texte et le vidéoclip de cette chanson-hommage à Denis Vanier se trouvent sur le site http://www.alexandrebelliard.com.]

+ DONTIGNY, Aimé et Diane LABROSSE, «Média tactique», Télépathie, Montréal, No type, 2003. [Remix de la lecture de Denis Vanier à la Nuit de la poésie 1970.]

+ DRILL, Jack [Richard Gingras] et les Pléiades, «1 lb. de beurre», «Offerts à la chasse», «L'évidence», «Casser la soif», «L'horreur des fruits» et "L'amie de personne», Lange et linceul, Montréal, Productions Steak Haché, 2004. [Poèmes de Denis Vanier mis en musique.]

+ LESBIENNES D’ACID, «Se battre ou pleurer», Les impénétrables, Montréal, Magada, 1997. [Poème de Denis Vanier mis en musique.]

+ LES SHIRLEY, «Denis Vanier», Mescaleros, Montréal, Indépendant, 2006. [Chanson-hommage.]

+ VOLLÉ, Yvan [Yvan Bilodeau], «Notre-Dame de la défaite», Yvan Vollé, Montréal, Atomic Productions/Disques Artic, 2001. [Poème de Denis Vanier mis en musique.] 